\title{
The Microstructure and Magnetic Properties of YIG Powders Synthesized by a Coprecipitaion and a Sonochemical Process
}

\author{
Seongmin Hong ${ }^{1}$, Yong-Il Kim² ${ }^{2}$ and Cheol Gi Kim ${ }^{1 *}$ \\ ${ }^{1}$ Department of Materials Science and Engineering, Chungnam National University, Daejeon 305-764, Korea \\ ${ }^{2}$ Korea Research Institute of Standard and Science, Daejeon 305-340, Korea
}

(Received 6 February 2009, Received in final form 2 September 2009, Accepted 3 September 2009)

\begin{abstract}
Nano-sized Yttrium iron garnet ( $\mathrm{YIG} ; \mathrm{Y}_{3} \mathrm{Fe}_{5} \mathrm{O}_{12}$ ) particles have been synthesized by using coprecipitation and a heat treatment process. The YIG particles were made using a nitrate or a chloride salt solution. The pH concentration of the solution was fixed at 12. Spherical shaped YIG particles were made with a size of about 20 $\mathrm{nm}$. The magnetization value of the particles was smaller than the bulk value but their coercive field showed a high value.
\end{abstract}

Keywords : YIG, coprecipitation, sonochemical method, nanoparticle

\section{Introduction}

Garnet structured materials have received a great deal to attention in the laser, microwave device and ultrasonic device fields. A variety of processing techniques have been investigated to form single-phase YIG powders [1], including coprecipitation, hydrolysis of metal alkoxides, and amorphous citrate gels. The coprecipitation method [2-4] has been used to control the process of precipitation because when particles are formed they may change according to the nature of the solution. The sonochemical method [5-7] has been used to control the uniformity of the particle. This method is able to fabricate nanoparticles at room temperature and also has the advantage of accelerating the chemical reactions. The magnetic properties of a given particle, such as saturation magnetization, remanence and coercivity, are critically dependant on the structure and the microstructure of the materials. Therefore, it is important to develop techniques to strictly control the production of garnets as it applies to their composition, homogeneity, size, and particle shape [2].

In this study, we give an alternative method to obtain nano sized spherical YIG particles, by using a coprecipitation technique and a sonochemical method, from the controlled hydrolysis of metal salts.

*Corresponding author: Tel: +82-42-821-6632

Fax: +82-42-822-6272, e-mail: cgkim@cnu.ac.kr

\section{The Experiment}

Yttrium chloride (99.9\%), iron chloride (97\%), yttrium nitrate $(99.9 \%)$, iron nitrate $(99 \%)$, and ammonium hydroxide were used as supplied by the manufacturer. The YIG amorphous particles were obtained through the hydrolysis of a metal chloride or a nitrate solution. The starting solution was a mixture of iron chloride and yttrium chloride in chloridic acid at $0.2 \mathrm{~mol} \cdot \mathrm{l}^{-1}$ or a mixture of iron and yttrium nitrates in adequate proportions. These solutions were mixed, according to the ratio of $\mathrm{Fe}: \mathrm{Ytt}=$ 5:3, and preheated to $90^{\circ} \mathrm{C}$. Afterwards, ammonia was added during the ultrasonication in order to increase the $\mathrm{pH}$ and improve the hydrolysis process [8]. The ultrasonication process ran for $1 \mathrm{hr}$ at $90^{\circ} \mathrm{C}, 750 \mathrm{~W}$ and 20 $\mathrm{kHz}$. The powders were then dried in a drying oven and heated in air to $800^{\circ} \mathrm{C}$ (for the chloride solution synthesis), and $850^{\circ} \mathrm{C}$ (for the nitrate solution synthesis) for an hour. Fig. 1 shows the sonochemical equipment and the preparation process of the YIG particles. The samples were then examined for their polycrystalline structure, spherical shape and for the appropriate magnetic properties. These samples were characterized through X-ray powder diffraction, transmission electron microscopy and a vibrating sample magnetometer.

\section{Result and Discussion}

Fig. 2 shows the X-ray diffraction pattern of the YIG 


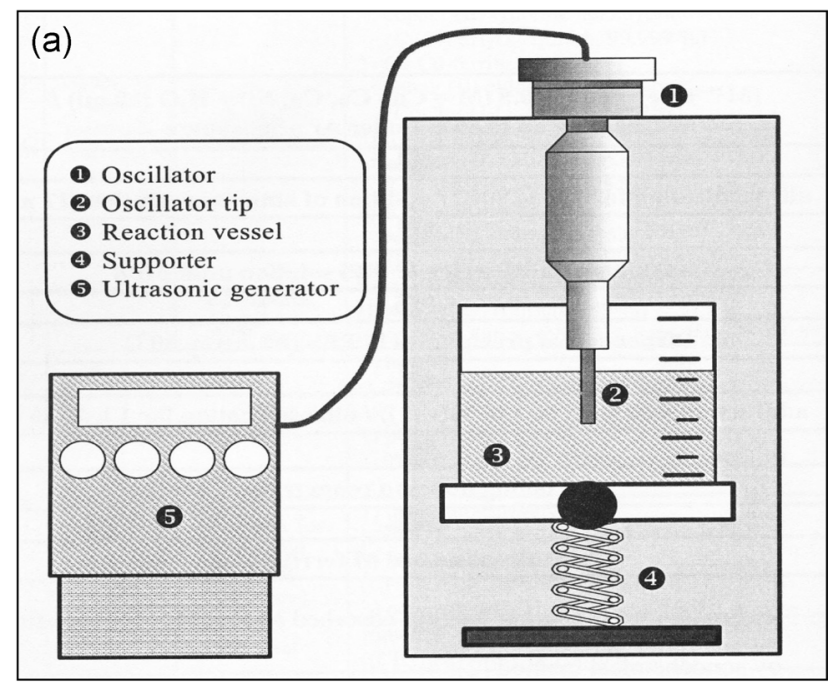

(b)

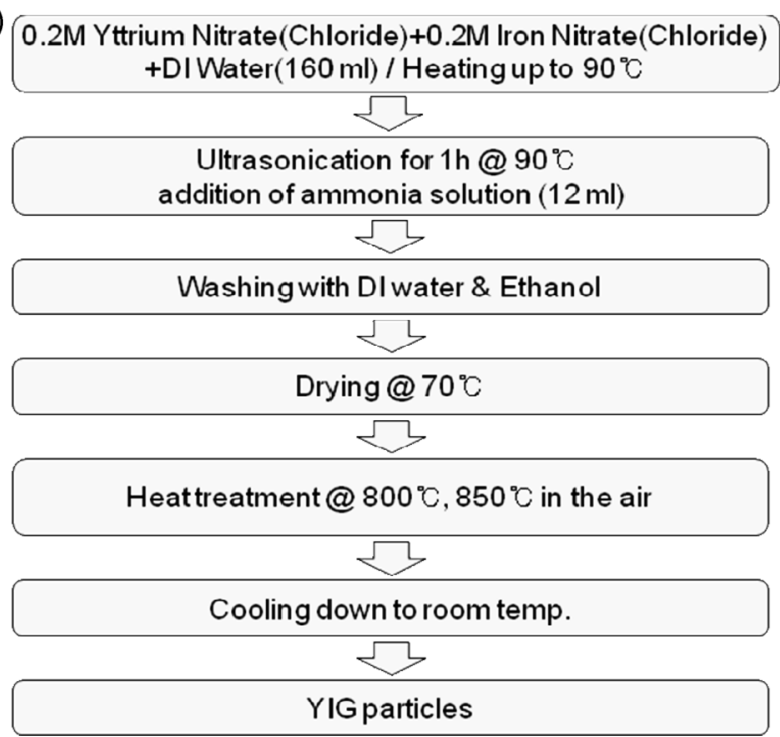

Fig. 1. The schematic diagram of the sonochemical equipment and the preparation process of the YIG particles.

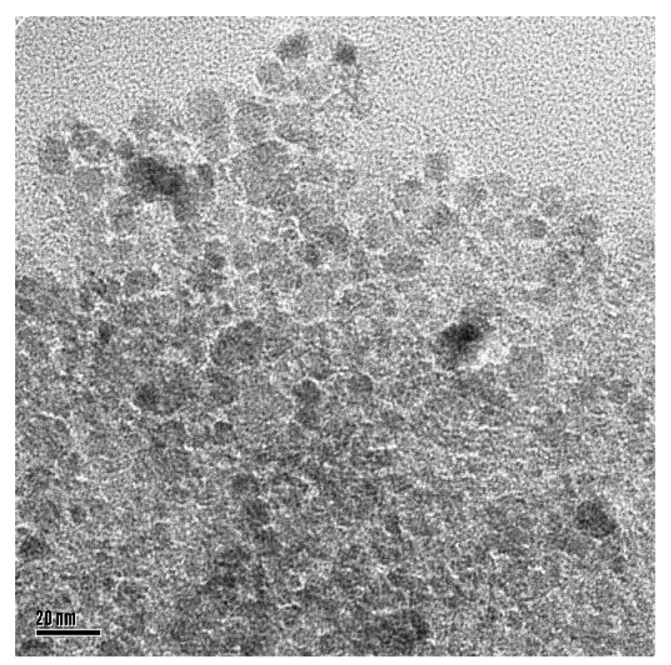

Fig. 3. The TEM image of the YIG particles (YIG-C 800).

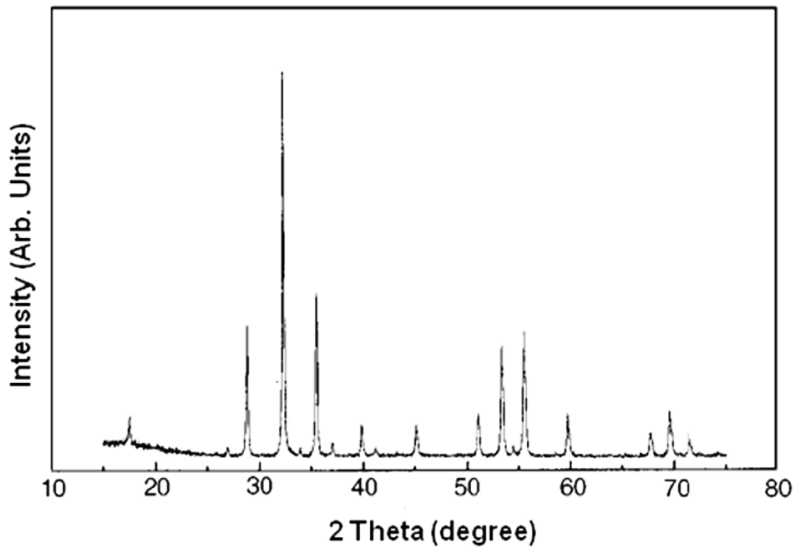

Fig. 2. The XRD patterns of the $\mathrm{Fe}_{3} \mathrm{Y}_{5} \mathrm{O}_{12}$ compound, heated at $800{ }^{\circ} \mathrm{C}$.

particles (YIG-C) obtained by heat treatment at $800^{\circ} \mathrm{C}$, which was made from the chloride solution. That pattern shows only the characteristic peaks made by YIG molecules. The same XRD peaks are revealed in the YIG particles (YIG-N) made from the nitrate solution treated at $850{ }^{\circ} \mathrm{C}$. The reason for the difference in the YIG formation temperature is due to the different starting solutions.

The transmission electron microscopy results seen in Fig. 3 show the size and the shape of the YIG particles made by the coprecipitation and sonochemical methods. Spherical shaped YIG particles are seen with the size of about $20 \mathrm{~nm}$.

Fig. 4 shows the hysteresis loops recorded at room temperature for the YIG-C 800 and YIG-N 850 samples. The loops exhibit ferromagnetic characteristics rather than superparamagnetic behavior. Table 1 shows the values of the magnetization $M_{s}$, the remanent magnetization $M_{r}$, and the coercive field $H_{c}$, measured at $3 \mathrm{kOe}$ and $6 \mathrm{kOe}$,

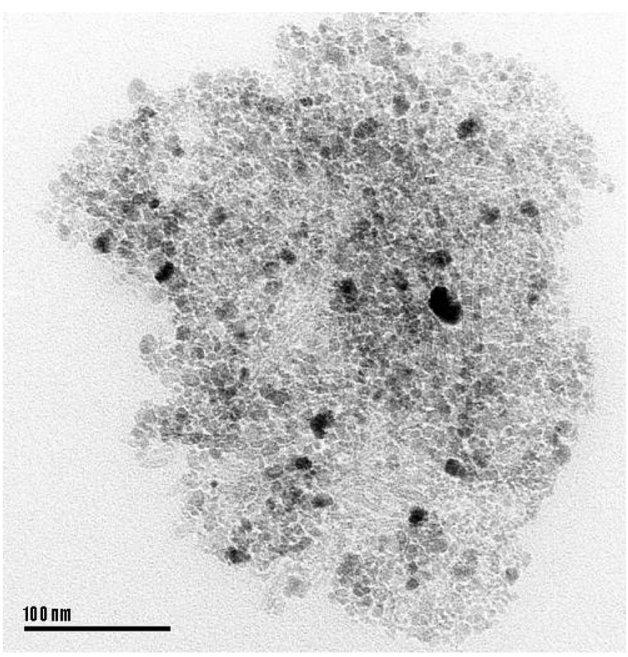



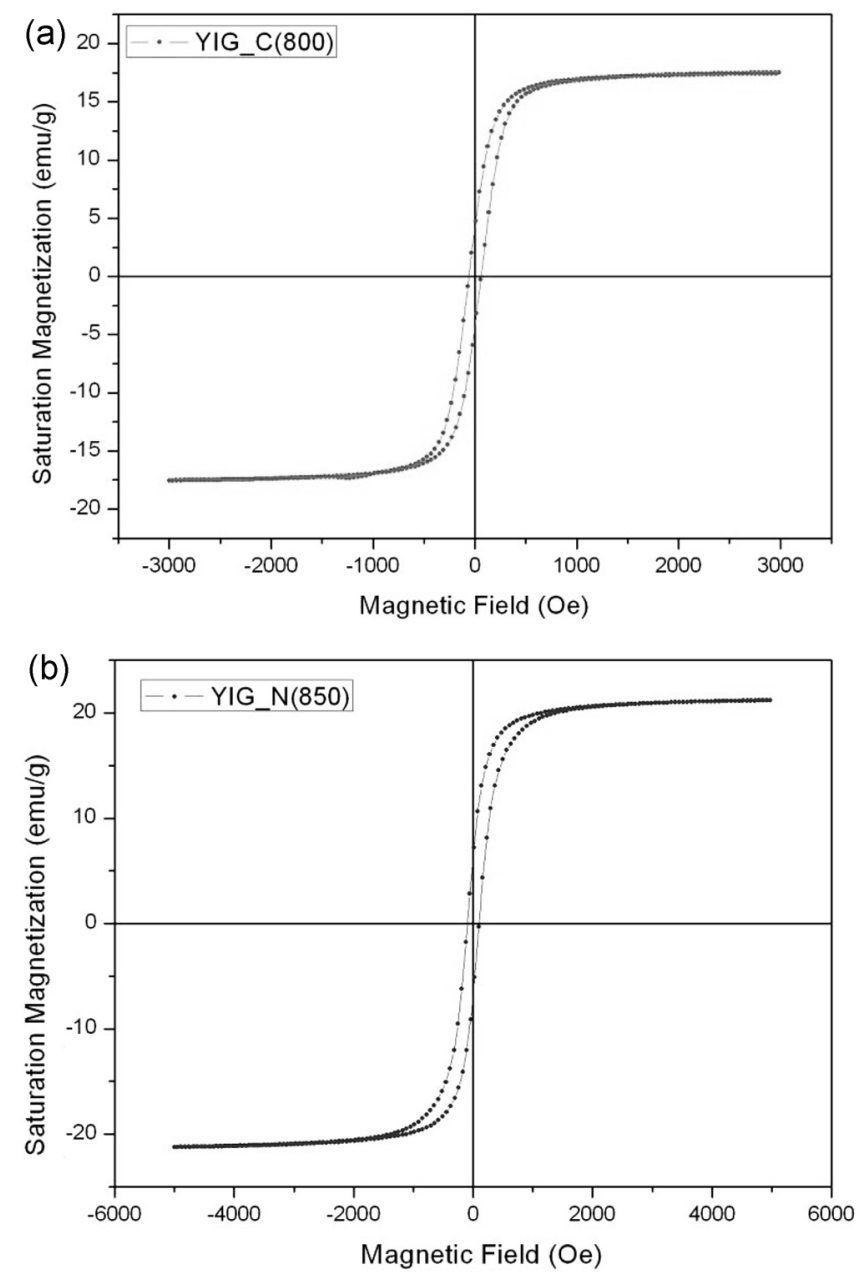

Fig. 4. The hysteresis loops of samples YIG-C 800 and YIG-N 850 , recorded at room temperature.

Table 1. The magnetic properties of the YIG samples.

\begin{tabular}{cccc}
\hline \hline Sample & Ms (emu/g) & Mr (emu/g) & Hc (Oe) \\
\hline YIG-C 800 & 17.6 & 4.4 & 58 \\
YIG-N850 & 21.3 & 6.9 & 95 \\
\hline
\end{tabular}

respectively, for the crystallized particles made at $800^{\circ} \mathrm{C}$ and $850^{\circ} \mathrm{C}$.

It must be emphasized that the crystalline samples show that their magnetization $\mathrm{Ms}$ is smaller than that of the bulk value (26 emu/g), as observed in Fig. 4 [2, 9, 10$]$. This discrepancy might be due to the existence of amorph- ous impurities undetected by the XRD patterns. The large coercive field might be due to a particle aggregation problem.

\section{Conclusion}

Nano sized YIG crystalline particles were synthesized from chloride and nitrate salt solutions by the coprecipitaion and sonochemical processes. The YIG amorphous particles were crystallized at $800^{\circ} \mathrm{C}$ and $850^{\circ} \mathrm{C}$, dependant upon which salt was used. Spherical shaped YIG particles were found with the size of about $20 \mathrm{~nm}$. The magnetization value was smaller than the bulk value but their coercive field showed a high value. These results might be due to the existence of impurities and a particle aggregation problem.

\section{Acknowledgments}

This work was supported by the foundation research project of the Agency for Defense Development and a grant from the Fundamental R\&D Program for Core Technology of Materials funded by the Ministry of Knowledge Economy, Republic of Korea.

\section{References}

[1] M. H. Han and Y. S. Ahn, J. Mater. Sci. 31, 4233 (1996).

[2] P. Vaqueiro, J. Rivas, and A. L. Quintela, J. Mater. Chem. 7 (3), 501 (1997).

[3] R. H. M. Godoi, M. Jafelicci Jr., R. F. C. Marques, L. C. Varanda, and R. C. Lima, Quim. Nova 22, 6 (1999).

[4] P. Grosseau, A. Bachiorrini, and B. Guihot, Powder Technol. 93, 247 (1997).

[5] S. F. Wang, F. Gu, M. K. Lu, G. J. Zhou, and A. Y. Zhang, Cryst. Growth 289, 621 (2006).

[6] K. S. Suslick, Science 247, 1439 (1990).

[7] Mark Hodnett, Rachel Chow, and Bajram Zeqiri, Ultrason. Sonochem. 11, 441 (2004).

[8] M. Jafelicci Jr. and R. H. M. Godoi, J. Magn. Magn. Mater. 226, 1421 (2001).

[9] C. D. Veitch, J. Mater. Sci. 26, 6527 (1991).

[10] S. Taketomi, K. Kawasaki, and Y. Osaki, J. Am. Ceram. Soc. 77, 1787 (1994). 